\title{
Dynamic Response Analysis of Blades with Damping Structures of Shroud and Snubber
}

\author{
Guoping $\mathrm{Li}^{1, \text { a }}$, Qiang Zhang ${ }^{2, \mathrm{~b}}$, Wei Zhao ${ }^{2, \mathrm{c}}$, Qin Zhou ${ }^{2, \mathrm{~d}}$, Yonghui Xie ${ }^{2, \text { e }}$ \\ ${ }^{1}$ Shanghai marine equipment research institute, No.10, Hengshan Road, Shanghai, 200031, \\ P.R. China \\ ${ }^{2}$ School of Energy and Power Engineering, Xi'an Jiaotong University, No.28, Xianning West \\ Road,Xi'an, Shaan Xi, 710049, P.R. China \\ aliguoping2001@sohu.com, bzhangq008@stu.xjtu.edu.cn, '467101312@qq.com, dzhouqin_s@163 \\ .com, ${ }^{e}$ yhxie@mail.xjtu.edu.cn
}

Keywords: Friction Damping; Blade; Contact; Response

\begin{abstract}
A method is developed to analyze the influence of friction structural damping on the vibration characteristics of turbine blades. Vibratory responses of a long steam turbine blade with shroud and snubber are studied. Finite element contact analysis of the steam turbine blades modeled in 3-D solid elements is conducted to obtain the normal contact force on the shroud contact surface and snubber contact surface of adjacent blades under a serious of different rotational speeds. The stiffness matrix elements and damping matrix elements are built between dry friction contact surface to simulate the frictional characteristics on the contact surface of damper and blade. The results show that with increases in rotational speed, the resonance amplitude decreases first and then increases when there is only shroud contact. The effects are similar when there are both shroud and snubber contact. Under the certain conditions, the increasing of excitation force can also degrade stiffness and damping of shroud and snubber.
\end{abstract}

\section{Introduction}

Turbine nowadays plays an extremely important role in industrial areas. As its core component, blade vibrates under the airflow excitation force and induces high cycle fatigue, which is one of the prime reasons for blade failure. Therefore, attenuating the resonant response and reducing the vibration stress to the allowed range are very important for the safe and reliable of the machine. By increasing the damping, the blade vibration stress could be reduced, which has become one of the most important and effective means. Dry friction damped turbine blade has been widely used by turbine manufacturers abroad in the important industry and key areas of the national economy, especially power stations, industrial drives and shipping. This blade has lower vibration stress, which guarantees the safe operation of the unit.

In recent years, the nonlinear dynamic characteristics of complex friction damping structure blades have been researched widely abroad. Yalin Liu et al. [2, 3] established a real turbine blade finite element model with the structure of dry friction damping shroud by using three-dimensional hexahedron units. Combined with the micro slip model, they obtained the damping vibration characteristics of the blade. Sanliturk et al. [4, 5] presented the complex equivalent stiffness associated with relative displacement amplitude by one-order harmonic balance method to describe the nonlinear characteristics of the friction damper. They also analyzed the response of blade vibration when damper was under the different positive pressure. Experiments were conducted for the verification. Panning, et al. [6] took the whole circle blade model with the hub platform damper as the research object and established a cycle symmetric finite element analysis model by using three-dimensional solid elements. They optimized the analysis of the damper quality on the condition of different geometric structure of the damper, different blade vibration shape and different exciting force amplitude. They reported that, in addition to the quality of damper, the geometric dimensioning of the damper and contact surface below the hub platform contact were also important parameters influencing vibration characteristics of the damping blade. 
Based on the research before, this paper researched the nonlinear dynamic characteristics of the high power turbine blade with the structure of a complex friction damping. According to the results of the three-dimensional contact analysis, blade vibration responses were calculated under different rotational speed, namely, different positive pressure at shroud and snubber contact areas. Meanwhile, vibration characteristics of shroud and snubber damping were analyzed.

\section{3-D Dry Frictional Contact Analysis Model}

In this paper, dry friction damped blade vibration response analysis model was established by three-dimensional entity element. According to Hamilton principle, the system motion differential equation of blades with the structure of the dry friction damping under the simple harmonic excitation can be expressed as:

$$
\mathbf{M} \ddot{\mathbf{X}}+\mathbf{C} \dot{\mathbf{X}}+\mathbf{K X}=\mathbf{F}+\mathbf{F}_{\mathbf{n}}
$$

where, $\mathrm{M}, \mathrm{K}, \mathrm{C}$ are the mass matrix, stiffness matrix and material damping matrix of blade structure respectively; $\mathrm{X}$ is the displacement vector; $\mathrm{F}$ is the external load matrix; $\mathrm{F}_{\mathrm{n}}$ is the vector containing dry friction, which is $f n$ at the junctions with friction damper, other place is $0 . f_{n}$ is the equivalent nonlinear force at the damper end, which can be expressed as:

$$
f_{n}=C_{\text {eq }}\left(\mathbf{X}_{\mathrm{c}}\right) \dot{\mathbf{X}}_{\mathrm{c}}+K_{\text {eq }}\left(\mathbf{X}_{\mathrm{c}}\right) \mathbf{X}_{\mathrm{c}}
$$

where, $\mathrm{X}_{\mathrm{c}}$ is the damping displacement. Harmonic balance method is a kind of ideal approximation algorithm for solving nonlinear dynamic equation. In general, it meets the requirements of engineering precision, and the computation speed is fast. For eq. (2), a multi-degree of freedom nonlinear differential equation, one-order harmonic balance method is adopted. Assuming the form of solution is:

$$
\mathbf{X}=\mathbf{X}_{\mathrm{a}} \mathrm{e}^{\mathrm{i} \omega t}
$$

where, $X_{a}$ is the vibration amplitude of the blade. With it substituted into in eq. (1), the nonlinear differential equation can be transformed to a nonlinear algebraic equation to solve. The transformed nonlinear algebraic equation also needs iterative solution.

The contact structures of the snubber and shroud of the long blade in the computation model are shown in Fig.1. All these finite element meshes of model is discretized with 8-node solid hexahedral element, guaranteeing the computation precision. Spring-damper elements are employed to simulate the friction damping effect between contact surfaces of adjacent blades. The total numbers of elements and nodes are 10388 and 7428, respectively.

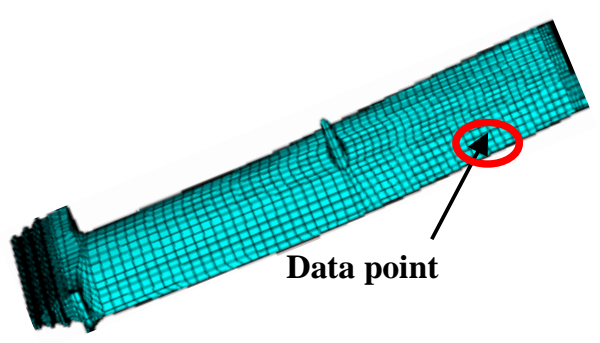

(a) Single blade
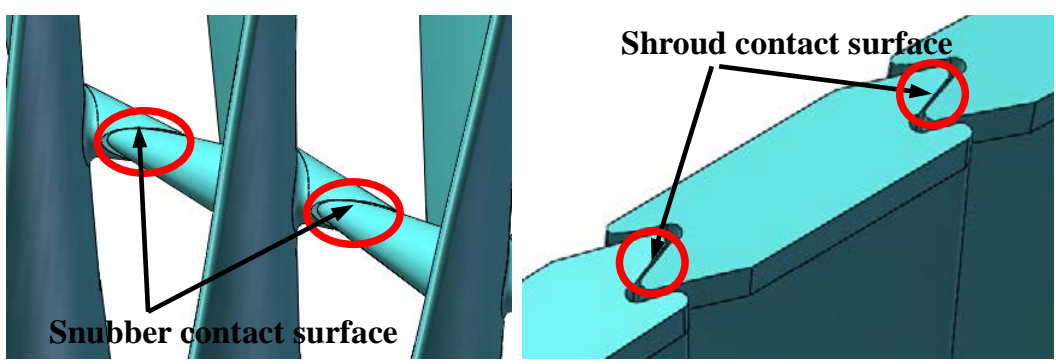

(b) Detailed structure of snubber

(c) Detailed structure of shroud Fig. 1 3-D contact configuration of blade

\section{Results and Discussion}

According to the contact analysis results, when the speed is less than 2413rpm, there is only shroud contact. And when the speed is greater than or equal to 2413rpm, the snubber and shroud contact surfaces all come into contact. Normal contact force on contact surface varies with the rotational speeds as shown in Table 1. 
Table 1 Normal contact force(NCF) on shroud or snubber contact surface under different rotational speeds

\begin{tabular}{cccccccc}
\hline Case & $\begin{array}{c}\text { Speed } \\
\text { /rpm }\end{array}$ & $\begin{array}{c}\text { NCF of shroud } \\
\text { /N }\end{array}$ & $\begin{array}{c}\text { NCF of snubber } \\
\text { /N }\end{array}$ & Case & $\begin{array}{c}\text { Speed } \\
\text { /rpm }\end{array}$ & $\begin{array}{c}\text { NCF of shroud } \\
\text { /N }\end{array}$ & $\begin{array}{c}\text { NCF of snubber } \\
/ \text { N }\end{array}$ \\
\hline 1 & 2200 & 1311.4 & 0 & 5 & 2500 & 1741.5 & 187.8 \\
2 & 2300 & 1454.3 & 0 & 6 & 2600 & 1921.4 & 340.7 \\
3 & 2413 & 1628.6 & 12.3 & 7 & 2800 & 2224.3 & 801.2 \\
4 & 2425 & 1640.2 & 37.5 & 8 & 3000 & 2475.7 & 1183.7 \\
\hline
\end{tabular}

Vibration response characteristics of the cases in Table 1 are analyzed. To facilitate this discussion, the vibration response amplitudes is expressed as a non-dimensional relative parameter $\alpha$, which is the ratio of response amplitudes under the above cases and the resonant response of free-standing blade under a steam excitation force of $2 \mathrm{~N}$.

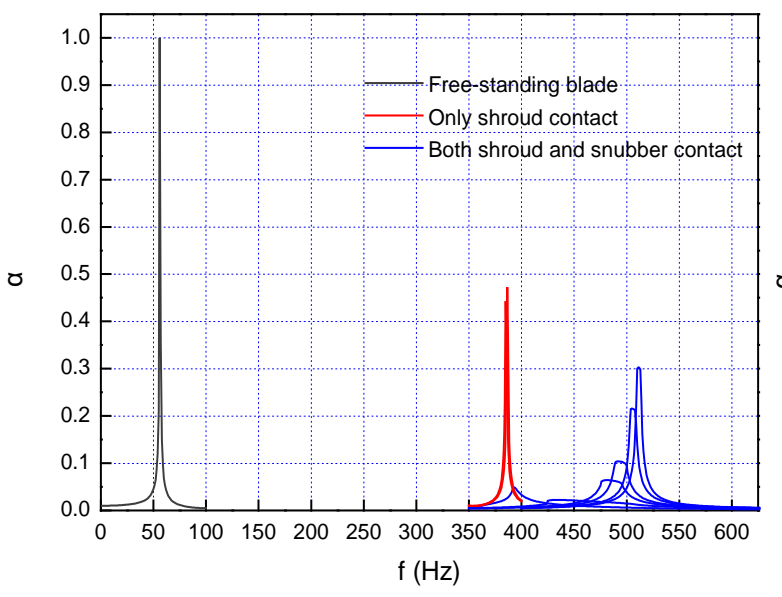

(a) Response curves in three different conditions

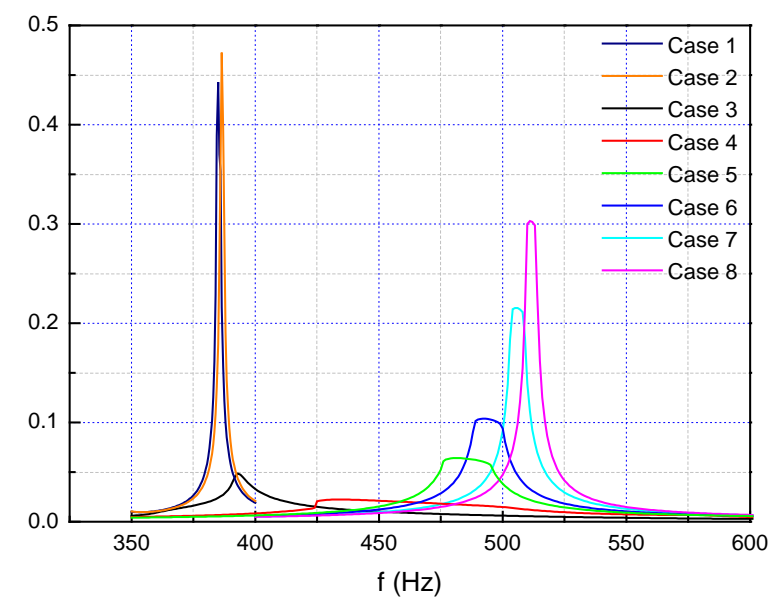

(b) Local magnification in each caces

Fig.2 Amplitude-frequency response curves of the data point

Fig. 2 shows the amplitude-frequency response curves of the data point in each calculating case. The resonant response is reduced significantly compared with that of uncoupled blade. The maximum relative amplitude $\alpha$ is only about 0.47 . Thus it can be seen that, the friction damping effect between contact surfaces of shrouds or snubbers can effectively dissipation of vibration energy of the blade. First the blade is free-standing, and then with increases in rotational speed the shroud contact occurs. In this process, with the increase of normal contact force the resonance amplitude decreases first and then increases, while the resonance frequency gradually increases. During the transition from condition of shroud contact only to that of both shroud and snubber contact, the resonance amplitude similarly experiences a decreasing period followed by an increasing one, and the resonant frequency rises further. This is due to the effect of nonlinear friction damping between contact surfaces.

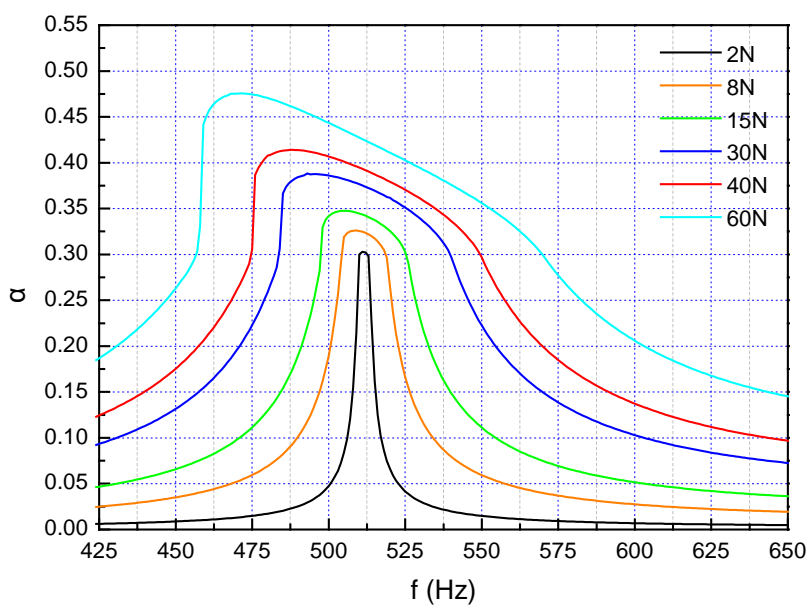

Fig.3 Amplitude-frequency response curves at different excitation forces 
Fig. 3 gives the amplitude-frequency response curves of the data point at different excitation forces. The stiffness degradation behaves in each curve. The amplitude of excitation force have great impact on not only response amplitude but also resonance frequency of blade system. When the amplitude of the excitation force increases, the response amplitude increases while the resonance frequency decreases; and vice versa.

\section{Conclusion}

Vibratory response characteristics of a long steam turbine blade with shroud and snubber were studied by using nonlinear three-dimensional finite element vibration analysis method. The following conclusions may be drawn:

1. When there is only shroud contact, with increases in rotational speed, the resonance amplitude of the blade decreases first and then increases, while a constant increasing is experienced when there are both shroud and snubber contact.

2. With increases in normal contact force, stiffness and resonance frequency of blade ever increases. And when the force is great enough, contact surfaces of shroud and snubber get into stick state, thus the system stiffness and resonance frequency take little change.

3. The increasing of excitation force can degrade stiffness and damping of shroud and snubber under the certain conditions.

\section{References}

[1] Csaba G. Modelling microslip friction damping and its influence on turbine blade vibrations[D]. Sweden: University of Linköping, 1998.

[2] Liu YL, Xu ZL, Gu WW, et al. Three dimensional friction contact model and its application in nonlinear vibration analysis of shrouded blades[C]. Proceedings of the ASME $201010^{\text {th }}$ Biennial Conference on Engineering Systems Design and Analysis. Istanbul: ESDA, 2010: ESDA2010-24669.

[3] Liu YL, Shangguan B, Xu ZL. A friction conatct stiffness model of fractal geometry in forced response analysis of a shrouded blade[J]. Nonlinear Dyn, 2012, 70: 2247-2257.

[4] Sanliturk KY, Imregun M, Ewins DJ. Harmonic balance vibration analysis of turbine blades with friction dampers[J]. Journal of Vibration and Acoustics, 1997, 119: 96-103.

[5] Panning L, Sextro W, Popp K. Optimization of the contact geometry between turbine blades and underplatform dampers with respect to friction damping[C]. Proceedings of ASME Turbo Expo 2002. Amsterdam: ASME, 2002: GT2002-30429.

[6] Yeh G. Forced vibration of a two-degree-of-freedom system with combined coulomb and viscous damping[J]. Journal of Acoustical Society of America, 1966, 39: 14-24.

[7] Yamashita Y, Shiohata K. Analysis of vibration characteristics for last stage blade with friction contact surfaces of steam turbine[C]. Porceedings of the ASME 2011 International Mechanical Engineering Congress \& Exposition. Denver: ASME, 2011: IMECE2011-63495.

[8] Petrov EP, Ewins DJ. Advanced modeling of underplatform friction dampers for analysis of bladed disk vibration[J]. Journal of Turbomachinery, 2007, 129: 143-150. 